\title{
Improved Learning Support with Minor Costs and Little Efforts: Students with a Disability in Higher Education and Their Perspectives of the Learning Support
}

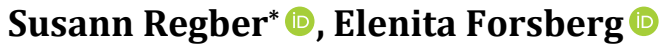 \\ School of Health and Welfare, Halmstad University, Halmstad, Sweden \\ Email: *susann.regber@hh.se
}

How to cite this paper: Regber, S., \& Forsberg, E. (2021). Improved Learning Support with Minor Costs and Little Efforts: Students with a Disability in Higher Education and Their Perspectives of the Learning Support. Creative Education, 12, 2624-2641.

https://doi.org/10.4236/ce.2021.1211196

Received: October 22, 2021

Accepted: November 22, 2021

Published: November 25, 2021

Copyright $\odot 2021$ by author(s) and Scientific Research Publishing Inc. This work is licensed under the Creative Commons Attribution International License (CC BY 4.0).

http://creativecommons.org/licenses/by/4.0/

\section{(c) (i) Open Access}

\begin{abstract}
In line with the sustainable development goals of Agenda 2030, the higher education institutions strive to achieve the values of an accessible and inclusive higher education for all students. The number of students with disabilities in higher education is rising in several countries. Studies exploring the students' perspectives of the learning support are lacking. This study explored the students' perspectives of the learning support provided for students with disabilities in higher education. Interviews with twelve students with various disabilities studying at a university in Sweden were held between 2018 and 2020. Data were analyzed using content analysis. Findings resulted in four categories: 1) A need for specific learning support based on each individual disability, 2) A satisfaction with the given learning support, 3) The student's disability in relation to their work-based internship, 4) The students' proposals to ease the study journey. In general, students appreciated having a mentor, a note taker, being able to sit in a smaller room during exams or having extended examination time. The students suggested improvements that could be realized with minor costs and small efforts. To meet the criteria of an inclusive and accessible higher education institution, a good learning support is of great importance.
\end{abstract}

\section{Keywords}

Accessibility, Students with a Disability, Higher Education, Learning Support, Qualitative Interviews

\section{Introduction}

Students with disabilities in higher education institutions (HEI) have the right to 
be ensured an inclusive and equitable quality education according to the sustainable development goals of Agenda 2030 (United Nations, 2020), but to achieve these goals, the voices of the students are necessary to take into consideration. In a study where students with disabilities were interviewed about the learning support (Majoko, 2018), several HEI barriers were reported, such as inflexibility of assignments and examination, lack of provision of handouts and focus on disabilities rather than abilities. The presence of students with disabilities is steadily increasing in HEIs in certain European countries (European Commission/EACEA/Eurydice, 2014; Stockholm University, 2019), but published studies about the formal support provided to students with disabilities are limited.

The share of registered, as well as non-registered students, with disabilities or longstanding health problem ranges from $7 \%$ to $39 \%$ between European countries according to the $6^{\text {th }}$ Eurostudent Survey (Hauschildt, 2018). The responsibility is on the student to present his or her disability, while the HEIs are responsible for offering appropriate adjustments for the students. Non-registered students who recognize having a disability (Hauschildt, 2018) but who choose to not make a medical or formal assessment are not allowed to request learning support (European Commission/EACEA/Eurydice, 2014). Reasons given by students for not disclosing invisible disabilities such as dyslexia, attention-deficit/hyperactivity disorder (ADHD) or autism spectrum disorders (ASD) are reported as a fear of being stigmatized (Evans, 2014), or being considered incapable or being "different” (Bolourian, Zeedyk, \& Blacher, 2018). Student's viewpoints concerning their disability within higher education have been studied from varying perspectives. Richardson et al. (2004) compared students who disclosed versus not disclosed their hearing loss. Olofsson et al. (2015) studied how students with dyslexia estimated their own abilities to study and how they managed their studies, and Evans (2014) how students in nurse education constructed their dyslexic identities. But there is a scarcity of studies focusing on registered student's experiences of the learning support for students with disabilities.

In an on-line Australian survey though (Anderson, Carter, \& Stephenson, 2018), students with ASD $(\mathrm{n}=48)$ indicated that they appreciated the learning support. In a Swedish survey with thirty-four registered students with Asperger syndrome, motor disabilities (MD), and deafness or hearing impairments (HD) (Simmeborn Fleischer, Adolfsson, \& Granlund, 2013), the researchers found that students with MD had more bodily difficulties, such as maintaining a sitting position for an appropriate length of time, and students with HD had hearing and communication problems, whereas students with Asperger syndrome mentioned difficulties to understand social interaction. On the other hand, all three groups of students had similar response opinions concerning perceived needs for learning support. For the HEIs, a diversity of disabilities is the array to take account for when offering directed learning support where some disabilities are more common, and others appear more seldom. 


\section{The Swedish Higher Education Context and Students with Disabilities}

The responsibility for higher education rests with the Swedish Parliament (Riksdag) and the Government of Sweden (Regeringen). Higher education is offered at 35 universities and other institutions of higher education. No tuition fees are charged for higher education studies in Sweden, and to cover the costs of living most Swedish students receive support from the central government, which is a combination of study grants and loans (Swedish Higher Education Authority, 2019).

The Swedish Higher Education Act, Chapter 1, Section 5 (SFS, 1992: p. 1434) and the Swedish Anti-Discrimination Act (SFS, 2008: p. 567) stipulates that HEIs must actively promote equal rights for students and widen recruitment to higher education. The student population is expected to reflect the population at large and include the participation of under-represented groups from educationally disadvantaged backgrounds, ethnic and religious diversity, diverse sexual orientation, and students with disabilities. Data on students with disabilities from all universities and other institutions of higher education is gathered at the Stockholm University (https://www.su.se/). In the academic year 2017/2018, the total number of enrolled students and graduates in first-cycle or second-cycle educational study programs was just over 400,000 (Swedish Higher Education Authority, 2019). The number of known students with disabilities who were given access to support resources provided by HEIs is steadily rising and amounted to 15,240 in 2017 and 20,150 in 2019 (Stockholm University, 2019). A prerequisite for receiving targeted learning support is that the student, by means of an attestation, certificate or investigation from an expert, can prove a permanent disability that affects their studies. Available directed learning support includes for example: extended time for taking exams and take-home assignments, technical aids, for example a computer with speech synthesis software (reading function), the possibility to write the examination in a small group instead of in a main hall, a sign language interpreter for students with serious hearing impairments, or support to get written interpretation from spoken language to written language, notetaking support by a fellow student, a personal mentor and obtaining certain course literature as a talking book, e-text book, in Braille or with enlarged text. In dialogue with the administrator for students with disabilities, the student receives a list of suitable learning support. But for adjusted exams, the administrator for students with disabilities can only give a recommendation. The examiner of the course decides which adjustments can be made, based on the learning objectives for the course.

Given the rise of registered students with a disability in HEIs and the scarcity of studies focusing on the students' perspectives of the learning support, this study aimed to explore the students' perspectives of the learning support provided for students with disabilities in higher education.

\section{Method}

In this study, a descriptive qualitative method was used (Polit \& Beck, 2012). In 
depth interviews were chosen to be able to catch each individual student's perspective on the learning support, according to how the disability affected their learning process.

\subsection{Participant Selection}

The study was performed at a university in Sweden. All direct contacts and recruitment of students with a disability were made via the administrator for students with disabilities, who also functioned as a gatekeeper to gain entrée to the students (Polit \& Beck, 2012). Interested students were given written and verbal information about the study. Twelve students were willing to participate. The students were then contacted by the researchers. The participating students (PS) were represented by a variety of disabilities, bachelor's degree programs, and gender were represented by females, males and transgender (Table 1). The PS also presented the following concomitant disorders: anxiety disorders, depressions, low resistance to stress, social phobia, squinting and visual impairment, perceptual problems and sleep disorders.

\subsection{Data Collection}

The individual interviews were conducted between December 2018 and March

Table 1. Participant's gender, disability and educational program. Values are numbers (n).

\begin{tabular}{lll}
\hline Gender & Female /Male/Transgender & $7 / 4 / 1$ \\
\hline Disability & Dyslexia & 4 \\
& ${ }^{*}$ ADD/ADHD/ASD & $1 / 1 / 1$ \\
& ${ }^{*}$ CP and wheelchair user & 1 \\
& Hearing impairment & 1 \\
& Spina bifida with hydrocephalus and ${ }^{\star}$ MD & 1 \\
& Specific language disorder & 1 \\
& Bipolar disorder & 1 \\
\hline Educational & $\dagger$ Preschool Teacher Education Program & 2 \\
program & $\dagger$ Primary Teacher Education, preschool class and school years $1-3$ \\
& $\dagger$ Upper secondary Teacher program in English and Swedish & 1 \\
& $\dagger$ Nursing Program & 2 \\
Social Change and Social Sustainability & 2 \\
Linguistic program, specialization in text editing & 1 \\
Business Administration and Economics Program & 1 \\
Environment, Innovation and Sustainability & 1 \\
Biomedicine Program & 1 \\
\hline
\end{tabular}

*Attention-Deficit Disorder (ADD), Attention-Deficit Hyperactivity Disorder (ADHD), Autism Spectrum Disorder (ASD), Cerebral Palsy (CP), Mobility Dysfunctions (MD), $\dagger$ Work-based internship included. 
2020, were audiotaped, and lasted between 20 to 56 minutes (median time 32 min.). All interviews were conducted jointly by the two researchers (SR, EF). Seven interviews were held face to face in a secluded room at the university while five interviews were held via a digital computer room, due to the Corona pandemic in spring 2020.

\subsection{Interview Guide}

A semi-structured interview guide with the following themes was used: 1) the student's description of their disability 2) how the disability affected the studies 3 ) the learning support used by the students 4) positive and/or negative experiences of using the learning support 5) if, and to what extent work-based internship education was included in the student's educational program 6) the student's disability in relation to their work-based internship 7) opportunities for social inclusion 8) a description of what has worked best in terms of opportunities to complete the studies and 9) the student's proposals for visionary improvements of the learning support.

\subsection{Data Analysis}

The transcribed interviews were imported into the computer-assisted qualitative data analysis software Nvivo 1.1 (NVivo, 2020) to assist in storing, sorting, coding, and analyzing the data. The content analysis described by Lindgren et al. (2020) with a manifest approach was applied. Data was divided into meaning units that were condensed into codes. These codes were then sorted into similarities and differences which were further abstracted into subcategories and categories. The analysis was carried out jointly by the two researchers (SR, EF).

\subsection{Ethics}

The study was approved by the Regional Ethical Review Board at the University of Lund, Sweden 2018-05-20 (J no. 2018/317). Ethical considerations were taken into account that students with disabilities may have experienced disappointment and shortcomings due to their disability. For that reason, the questions in the interview guide were only based on the educational situation with regard to the informant's integrity. Measures were also taken to create a warm and permissive atmosphere during the interview.

\section{Results}

Our analysis resulted in 367 meaning units, which were further condensed into codes resulting in fourteen subcategories and four categories (Table 2).

\subsection{A Need for Specific Learning Support Based on Each Individual Disability}

\subsubsection{Dyslexia and Specific Language Disorder}

Students with dyslexia and specific language disorder explained that it takes a longer time to read, that they don't spell the words but copies them in their 
Table 2. Classification of categories and subcategories.

\begin{tabular}{ll}
\hline A need for specific learning & $\begin{array}{l}\text { Dyslexia and specific language disorder } \\
\text { support based on each }\end{array}$ \\
individual disability & $\begin{array}{l}\text { ADHD, ADD and ASD } \\
\text { Bipolar disorder } \\
\text { Cerebral Palsy and Spina Bifida }\end{array}$ \\
& Adjusted form for examinations \\
A satisfaction with the given & $\begin{array}{l}\text { Technical support } \\
\text { learning support }\end{array}$ \\
& $\begin{array}{l}\text { Personal support } \\
\text { The student's disability in relation }\end{array}$ \\
to their work-based internship & $\begin{array}{l}\text { To be acquainted with routines } \\
\text { To be a role model to bridge tolerance for disabilities }\end{array}$ \\
The students' proposals to ease & The administrative environment \\
the study journey & The learning environment \\
& The built environment
\end{tabular}

minds: "If I am going to read a chapter, I have to reread the chapter, page or paragraph several times in order to understand the essence of the sentence, and it takes time. You have to memorize." (PS 11) The student with a specific language disorder had difficulties with mixing words: "Yes! I mix up words so that sentences can get a little crazy if I write the wrong words. (PS 3)

Students also mentioned positive experiences with their disabilities. One student commented: "Yea, there are advantages to one's disability, it's not only disadvantages. I easily recall, and for me it is super easy to listen to texts or information, to add and remember details." (PS 12) And another student used to remember numbers by creating patterns and explained: "I use codes for port codes and gates and such, and then I think in patterns, not in numbers." (PS 2)

\subsubsection{ADHD, ADD and ASD}

The principal problem for students with ADHD and ADD is difficulties with concentration. The ability to maintain concentration for longer periods are reduced which affects the studies. Due to the concentration problems, teachers have been informed to keep to the $45 / 15$ rule, which means that the students get a 15-minute break after 45 minutes of lectures, described by one student: "it is the concentration that is very difficult [...] if they didn't have the $45 / 15$ system it would have collapsed for me. I cannot stay focused for very long. If there are about 100 people in a room and someone will drop the pen, then my brain is right there, so I know who it was and what happened without even thinking about it. Then I usually lose focus very easily." (PS 10) The same student gave another explanation on how this disability had an effect during written exams: "I know I cannot concentrate when I sit in large halls and do exams where I have to super focus. My focus will go away, and I will think 'what is the color of the curtains?'; To be able to perform as one should do on an exam, I need to have a smaller room where I sit alone, or maybe with only one other person.” (PS 10) 
The student with ADD described that he/she is processing written material slowly and that reading several books during a semester affect the studies a lot: "If I am going to read a book, I often need to read it many times, to be able to understand what they mean. And sometimes I have to ask someone else who reads through that part and then explains it to me." (PS 9)

Positive effects of having ADHD as a diagnosis was described by this student: "But I find it very easy to interact with others, talk to people. So, I think I help myself to be able to get in touch with people and to start conversations, to make it flow and not be so very stiff. I would say that my disability then supports... or helps me, so to speak. (PS 10)

The student with ASD described sleep disorders as one of the biggest concomitant disorder problems affecting the studies: “... my sleep schedule is quite irregular. Some weeks it can be down to ten hours a week, and most days it's no more than four, five hours a night. There is a lot going on in my head all the time, so to speak." (PS 6)

A lot of stress and anxiety was also described as a part of concomitant disorders affecting the studies: "The pressure is too much. So that's what my support is often about, reducing stress by means of preparation." This student highlighted another aspect that raised anxiety as being selected or pointed out by a teacher during a lecture: "If I raise my hand, it's because I'm ready to answer. If I don't raise my hand, I am not prepared to answer, the situation causes anxiety and fear of making mistakes... it's too much, and then I rather leave the room than answer a question I cannot answer." (PS 6)

The student with ASD also highlighted positive effects which were the heightened ability to understand and cope with different logical systems within certain subjects in higher education which match the need for structure in this diagnose. (PS 6)

\subsubsection{Hearing Impairment}

The student with hearing impairments is quite dependent on the lecturer's behavior in the classroom. Besides the headphones, the student uses lip reading to be able to follow the lecturer: "If I don't have my headphones, I hear absolutely nothing. So that's why it affects my studies a lot. I need to always see the lecturer's lips, which can be a little difficult if they turn around and start talking to the blackboard." (PS 7). To be able to concentrate on the lip reading as well as the contents of the lecture is exhausting for the student: "I get much, much more tired with listening intensely."

Sounds that hearing people can sort out are somewhat amplified for people who wear hearing aids. This was explained by the student: "I can experience that I am more easily disturbed in the examination room. The thing with using hearing aids is that they don't only raise the volume just around you, they also raise the volume at the far end of the corner. So that all the chair scratching, all the rustling, everything, the volume is raised in my hearing aid. And I still need to have them on ..." (PS 7) 


\subsubsection{Bipolar Disorder}

The student explained how the bipolar disorder affected the studies from being hyper manic as very creative, full of ideas and performing excellently and the contrary is the hypomanic period which is characterized by feelings of depression and fatigue. Medication harmonized the tops and downs and helped the student a lot to manage the studies: "So, when I get depressed, then I just must put everything away $[. .$.$] you become kind of very sensitive and very insecure$ about yourself, and just super tired mentally. But these periods are better after having started medication." (PS 8)

\subsubsection{Cerebral Palsy and Spina Bifida}

Physical disabilities are visible, but motor dysfunctions may not be the only disability. The student using a wheelchair reported: "My disability is visible, it is a $\mathrm{CP}$ injury, and then people think of it as a motor difficulty, and yea it is. But there are perceptional difficulties due to the cerebral hemorrhage and where it has settled in the brain. And those aspects are not understood at the university and I feel that we must develop a greater understanding there." (PS 1)

The students with physical disabilities as $\mathrm{CP}$ and spina bifida also mentioned concomitant disorders as perceptual dysfunctions: I need to have full focus on taking notes, for example, and listening at the same time. But when you don't have a perception problem and when you think of something, you can zoom in and out. But when you have perception problems, it can be difficult to find your way back, it takes a little longer. This with details is so difficult with the perception problem, for example at written exams, I need to have the paragraphs in different colors so that I can more easily divide it, and that it may also be easier to sort out. (PS 1) The student with spina bifida mentioned that problem with memorizing also could affect their studies: “.... also, the memory can be affected ..." (PS 5)

\subsection{A Satisfaction with the Given Learning Support}

\subsubsection{Adjusted Form for Examinations}

Some students were recommended by the administrator to obtain learning support in order to be able to take their exams orally rather than written, but only after an agreement between student and the examining teacher. One student explained that barriers could arise: "It was stated in the papers that we would get it, but it was not something that immediately seemed easy." (PS 3) Other students with social phobia or high stress levels applied for the reverse, i.e. written exams instead of verbal exams: "There may be exercises where you may have to give a speech or something like that, but you may not need to do it in front of the entire class, maybe only for the teacher and another student. Or if it is possible, do it in writing." (PS 6)

Several of the students mentioned: extended time, an extra week for written home assignments and being able to sit in a separate room at written exams as highly appreciated and positive learning supports: "When I make written indi- 
vidual exams, I have extended time with two more hours (PS 8), "When I do written individual exams I use all the support I have; own room, a computer and double time, which is for example six hours when the exam time is three hours." (PS 9) I'll do the home written exam just like everyone else, but the only difference is that I can email that I might want a few extra days or so." (PS 5)

\subsubsection{Technical Support}

Several of the students use the spellchecker support on the computer but also special programs such as a strengthened spellchecker programs, speech synthesizers and recorded books (talking books). One student described a spellchecker program: "Stava Rex" is a program that reads out texts that you write in Word documents, so when I write a text, I can listen to the text later. But spelling mistakes can be difficult to distinguish, because the spelling program only helps to some extent. There are words that have a different meaning, and these words can be very wrong in a context. I can hear it is wrong, but I may not be able to see it because the spelling program does not indicate it." (PS 12)

Many of the students with dyslexia and language- and perception disorders were pleased to use a support tool from the library called LEGIMUS (talking books): "LEGIMUS" is a library service, which is provided for those who have a certain type of problem with reading. And in that service, you look up the book and name the author, then you have it in front of you and in digital form. You can either read the text just like that or you can listen to it and read at the same time. So that's what I have started to do now, to read and listen at the same time, because then I feel that I get the information better. (PS 1)

But one student also mentioned negative views about the talking books support: "I wish there was a larger selection because sometimes it is quite old literature available at LEGIMUS, and the course coordinators may want the latest edition, in a specific edition or book [....] to get a book recorded can take up to three months" (PS 11) and another student's said:" The speech synthesis is quite boring to listen to, so I don't use it." (PS 1)

To have a portable microphone or hearing loop which goes directly between the student and the speaker was the most positive learning support according the student with hearing impairment.

\subsubsection{Personal Support}

A mentor can be a support in planning and structuring the studies and also have a meaningful social duty in contact with the students. The mentorship is carried out by a teacher or by another student. The possibility to receive this support is based on having a suitable mentor on hand:

"Then I have a mentor, which helps me set up schedules and so on, and she is very good at planning and structuring and she is also a student at the university." (PS 6)

Irrespective of disability, note taking support was necessary for several students: "Because the biggest problem for me is that I cannot write down and at 
the same time focus on the lecturer speaking, because then I don't hear what the person is saying and I only get half sentences written down." (PS 9) The student fellows taking notes get a subsidy for this duty and are in general chosen by the administrator for students with disabilities: "It was me and two others who had dyslexia, and we had the same person who took notes for us." (PS 4)

\subsection{The Student's Disability in Relation to Their Work-Based Internship}

When students do the work-based internship, there is no specific learning support, but the students come up with different solutions to meet the challenges.

\subsubsection{To Be Prepared}

In some educational programs, a work-based internship is included as part of the educational program (Table 1). A student with dyslexia in the teacher education program described the extent of time used for preparing lessons for the work-based internship: “I always prepare myself. I don't read a single book aloud without having read it myself at home before, aloud. Because if I end up in a complicated word, I use the sound technique, and it does not work on reading aloud. My strength is that if I have read the books once, then I usually have it in my head and read with empathy" (PS 12)

Another student in the preschool teacher education program, also with dyslexia, described situations when reading books for the children: "Of course, you read fairy tales for children but then you must know that I work with children between 1 and 6 years, so when you read a book it is not the same level of difficulty, and no one would laugh at you if you say something wrong because the children don't know what is written in the book and it does 't matter if you change certain words." (PS 3)

\subsubsection{To Be Acquainted with Routines}

A nurse student with dyslexia explained the differences between reading the patient's health journals and to receive a verbal report from another nurse about a patient. The student did not find it difficult to read the journals, but it was more difficult to understand and acquire the verbal report. Another problem was the difficulties to transform an experienced event to a written document or paper: "I think it works well when you read the report yourself and you can take the time it needs, but to get a verbal report is sometimes harder. Because then you don't know everything about the patient in advance." (PS 4)

\subsubsection{To Be a Role Model to Bridge Tolerance for Disabilities}

A teacher student with visible disability explained challenges when meeting teenagers at the work-based internship in a school: "When you come to a school and sit in a wheelchair and you are a student teacher, then it can be a lot of 'fun' for some students to make fun of and tease this person who comes, maybe even more when one is in a wheelchair, because you will then be exposed. I had to put up with that. But that's the kind of thing I just have to get used to." (PS 1) At the 
end of the teacher training internship the students were asked by their regular teacher to write a personal letter to the student teacher about what they had liked about having the student teacher in the classroom. One student wrote in their letter: "it was interesting that you sat in a wheelchair, and I mean that in a good way." (PS 1) Another student with a visible motor dysfunction was studying the Preschool Teacher Education Program and did their teacher training internship with preschool children. The student described his/her difficulties with moving fast and therefore it was necessary to inform the staff: "I am not as quick to act as they are, but I still think they have understood that. Many people think that it is more of an asset to be different in the preschool." (PS 5)

\subsection{The Students' Proposals to Ease the Study Journey}

\subsubsection{The Administrative Environment}

Some students mentioned the lack of information about the existence of the learning support and meant that it would have been an advantage to get information earlier, already when applying for courses at the university: "I think it is of importance to show directly what there is to get when it comes to the learning support service. It was only when I talked to our administrator for learning support that I found out what kind of support there was to get." (PS 10)

Another student wanted to get non-written information in addition to the written: "Maybe it could be included in such places where it is easier accessible than written information. Because if you have learning support, then it is often that you don't read a lot of information." The same student also proposed the contact with the Student Union as a forum for disseminating information: "since they always call you up for a welcome invitation to the university, maybe they could also mention that students with disabilities are allowed to get individualized learning support." (PS 8)

One student proposed reductions of registration requirement of the exam registrations. The actual steps included both a digital report and then yet another written application to get access to the learning support.: "I think it would be easier if you had this form on the digital student-registration page where you could tick a box and attach this particular form, with which course it applies?" (PS 11)

\subsubsection{The Learning Environment}

A student support network would have made it easier to meet students in the same situation to not feel so alone: "Because we did that before one of the exams last semester, that we organized ourselves and sat in a study group at the library and studied two hours a day, for two weeks, and it helped a lot. There were many who said that 'I would not have passed the exam if we had not studied together'." (PS 6)

Another improvement proposal was to get an example of a lecture held at the university: "One idea I have had before and thought about, is that there might be examples of lectures. What can a lecture look like on this course? So, you are not 
completely unprepared for what might be expected." (PS 6)

Several students mentioned the contact with a mentor as an appreciated learning support. Additional individual support at the work-based internship was another service that needed to be strengthened according to one student: "I think that the university teacher might check if it works in reality so that you might get a little extra supervised support." (PS 5)

A student with dyslexia requested greater tolerance and acceptance for students with disabilities: “...when it comes to talking about individuals with disabilities we are not talking about their strengths, we are only talking about weaknesses ..." (PS 12) The student with hearing impairments desired to get more recorded lectures: “.. because then you can pause when you want to make notes. " (PS 7) Another improvement that was proposed was to provide the students with lecture material in advance: “... the teachers would post the PowerPoint projects on the learning platform before the lecture, kind of any day before, so you could go through them yourself." (PS 4)

\subsubsection{The Built Environment}

The physical accessibility for students with both visible and invisible physical disabilities proved to have the potential for improvement. The infrastructure at the university had certain technical deficiencies such as door openers that didn 't work. A student who was a wheelchair user explained that it was very frustrating to ask other people for help and besides very annoying when for example an automatic door opener does not work and there is no one there who can open the door. The student said: "Then of course I can try to call someone, but sometimes I don't know who I should turn to, and I have informed teachers that some door openers to certain buildings are shut off from time to time." (PS 1) The student developed these arguments by saying that this also affected the sense of autonomy, because autonomy is a matter of great importance since for individuals with physical disabilities you get another perspective of autonomy. Door openers were also not adapted to all toilets, and some of the doors were quite heavy to open when sitting in a wheelchair.

A student with congenital spina bifida and invisible motor dysfunction preferred that all lectures were held in the same building because of difficulties with walking longer distances. The student also mentioned that a special chair that maintains an ergonomic sitting position could have been stationary if the lectures had been held in the same building. For the student with a hearing impairment, it was of importance that teachers used microphones when keeping lectures.

\section{Discussion}

The implementation of accessible and inclusive higher education for students with disabilities is embedded in goal four in the Sustainable Development Goals (SDGs) of Agenda 2030 (United Nations, 2020). This requires that HEIs do not only have an accessible built environment but also an inclusive teaching and 
learning environment (Bencini, Garofolo, \& Arenghi, 2018). In this qualitative interview study, the participating students were surprisingly content with several of the learning supports that were offered to them. The informants expressed approval with having a student fellow taking notes, and those who had been assigned a mentor were satisfied to get help with planning and structuring the studies. The students with concentration difficulties appreciated the possibility to take their tests in a separate room or in a smaller group, which meant they did not need to be distracted by other students by, for instance, hearing a pen dropping to the floor. Another very appreciated learning support was the extended time for taking exams. The students also highlighted the need of getting recorded lectures and audience copies in advance. Teachers who could provide breaks and stick to the 45 minutes lectures followed by a 15-minute pause were heavily appreciated by students with concentration difficulties. To not being selected or pointed out by a teacher during a lecture, if their hand was not raised, was important for the student with ASD, so as to reduce anxiety and fear of making mistakes. The student with hearing impairments was dependent on lip reading and that teachers were aware of this and didn't turn to the blackboard during lectures. In agreement with the results of this study, other researchers have also reported that learning supports have been useful and appreciated when the voices of students with disabilities have been heard (Anderson et al., 2018).

However, the informants also revealed needs that could have been improved with relatively little effort and an individual approach. For example, a student who had difficulty walking longer distances due to an invisible mobility dysfunction wanted all lectures to be held in the same building. The same student also desired to have a stationary special chair to maintain an ergonomic sitting position. Although the built environment in a university campus often has several buildings spread out over the campus, an individualized support concentrating the lectures to only one building might have been a solution for this student.

Another example was a student being a wheelchair user who was dependent on the functionality of the push-pad openers on the building doors. When the door openers didn't function, which happened from time to time, there was no special telephone number where a building superintendent could be reached who could help open the door. The student stated that it was not only frustrating and hassling missing a lecture, but also affected the sense of not being autonomous. The value of feeling autonomous by students having a disability is confirmed by Adefila et al. (2020). The authors refer to the theory of self-determination to enable students with disabilities to utilize their autonomy and capability, implicating that autonomous individuals are better motivated to reach their goals and that an individual's feeling of being a valued member of a community is also the feeling of being a contributing member. One could therefore argue, in line with Adefila et al. (2020), that some individualized adjustments are reasonable to achieve, as in this case, while on the other hand others are expensive or difficult to operationalize and therefore may not be reasonable.

A lot of our participating students had difficulties to read written information 
and to navigate in learning platforms on the university's website. To increase the accessibility, improvements to be accomplished with limited costs and efforts, short videos that describe the variety of the learning support that is offered at the particular university could be produced. This suggestion is in agreement with the findings from a study of Redpath et al. (2013) who interviewed thirteen Irish students with a disability. The Irish students highlighted that it was important for the learning support services to publicize the services via various media formats, i. e. non-written information in addition to the written, but also to commence to publicize before or at arrival at university.

The students use of technical support such as talking books and spelling applications need to be steadily updated to be more attractive to the students. The student participants mentioned that the talking books were not always the latest edition and the spelling application had a robot voice that was tiresome to listen to. Since these technical devices are purchased by external producers by the HEIs, the negotiation between users and developers could be more focused more towards of the needs of the students, so that the devices could be improved. For example, the recording of course literature needs to be updated to the latest editions and instead of a robot-sounding voice, replace this with the voice of a human being.

The included work-based internship was carried out by six of the participating students in this study. The nursing students did their internships in a hospital or primary health care, and student teachers did their internships in a preschool-, primary school, or upper secondary school as part of their educational studies. In contrast to Adefila et al. (2020) the participating student's experiences with the work-based internship in this study, did not experience attitudinal barriers, stigma or prejudice, on the part of the educators or mentors at the workplace. Instead, the participating students explained that they rather acted as role models to bridge tolerance for diversities and disabilities. For example, a student with invisible mobility dysfunctions had to tell the staff at the preschool practice that running fast was impossible, due to the disability. But the student was met with tolerance and the opinion that it is an asset to be different at the preschool. This accepting attitude by the mentors at the student teaching placement may indicate that the preschool staff were acquainted with the Sustainable Development Goals of Agenda 2030 (United Nations, 2020). These goals form a value base that is applied at all levels of education. Another example was the teacher student who was a wheelchair user who was psychologically prepared to be teased when meeting teenagers at the work-based internship in school. But when the students were asked by their regular teacher to write a personal letter to the student teacher when ending the student teaching period, one student wrote that "it was interesting that you sat in a wheelchair, and I meant that in a good way." The student's impressions and reflections show that the personal contact and interactions with the student opened up for yet another bridge of tolerance.

However, tolerance and acceptance were questions of concern also for the 
participating students in this study. A student with dyslexia highlighted that there are still a lot of efforts to be made before tolerance and acceptance for individuals with a disability are fully met. The student explained that the idea of searching for weaknesses instead of looking for the strengths of an individual with a disability still prevails. This student pointed to an important aspect which is the medical model's view of the student with a disability, based on the assumption that the "disability" itself has to be compensated for (Järkestig Berggren, Rowan, Bergbäck, \& Blomberg, 2016). In agreement with the findings of Järkestig Berggren et al. (2016) who studied students with a disability in the Czech Republic, Sweden and the United States, our participating students also strived for being "the ordinary" student who strives "to succeed as a student in the institutional context of higher education" (p. 349). They emphasized that they also had positive experiences of their disabilities, such as the student with dyslexia who could easily listen to texts or information and retell and remember details, and the student with ASD who highlighted the positive effects concerning the heightened ability to understand logical systems within certain subjects in higher education, and the student with ADHD who could easily interact, and talk to people, which was seen as a positive side effect of the disability diagnosis. Other researchers confirm these findings; Olofsson et al., (2015) declared that most students with dyslexia can compensate for their reading disability, Anderson et al. (2018) reported several academic strengths among students with ASD as for example attention to details, technology skills, original and creative thoughts, strong memory, and consistency and D'Alessio and Banerjee (2016) underlined the importance for students with ADHD to understand and appreciate the unique strengths they bring to the learning environment beside the challenges and academic strategies for success. A holistic and a student-centered approach need to consider also the strengths that come alongside the individual student.

\section{Strengths and limitations}

The findings presented in this study have certain limitations. The study was conducted at only one single university, excluding students experiences from various HEIs. Another limitation is the small sample with only twelve participating students. But still the selection ended up being a broad diversity concerning gender and educational programs. The study participants also represented a variety of disabilities which in contrast to a study where all students had shared the same disability, it is difficult to draw any conclusions of similarities associated to a specific disability. An advantage of conducting a study at the same HEI is that the students share the same experience of the administrative and learning support adopted at the HEI which at a certain extent guarantees representativeness of the results.

Another strength is that the administrator of the learning support acted as a gate keeper which implicates that the students participated voluntarily. As researchers we didn't have any influence on the selection of students, but still the 
selection ended up being a broad variety concerning gender, disabilities and educational programs.

\section{Conclusion}

In general, the students were satisfied with the learning support they had received. The students confirmed the importance of a well-functioning learning support to succeed with their studies and to get entrance to the labour market. To ease the studies and the accessibility, the participating students suggested improved individualized learning support with minor costs and little effort. Already at start, the students wanted more thorough information about what there was to get out of the learning support and that the information was also given in a variety of media formats. Administrative rules can be barriers when students register for coming exams and need to be facilitated. According to the built environment, reasonable adjustments were suggested by the students such as being able to have lectures in the same building or to have a telephone number to be able to call when a door opener doesn't function. The teaching staff needs to have a flexible attitude vis-à-vis adjustments to the needs of the students with disabilities. To be an inclusive and accessible HEI, the teaching staff, administrative staff and policy regulations need to be continuously updated to meet the needs of students with a disability. To meet the criteria of an inclusive and accessible HEI, a good learning support is of great importance.

\section{Practical implementation}

Based on the findings in this study, practical measures were: 1) to enhance the information about the very existence of the learning support and add non-written information; 2) to reduce the registration requirements of the exam registrations; 3) to provide students with lecture material in advance; 4) to use a microphone when keeping lectures for students with hearing impairments; 5) to organize most of the lectures within the same building for students with physical impairments; 6) to provide a telephone number to contact a person who could help when doors are closed or too heavy to open, when sitting in a wheel chair, and 7) a mentor is an appreciated support who can help in structuring the studies.

\section{Acknowledgements}

We thank the student participants who contributed to this study and the administrator for students with disabilities for the support in the recruitment of the students. We are re also grateful for grants from the Federation of Nurses Educated at Sahlgrenska Academy, Gothenburg, Sweden (Kamratförbundet Sahlgrensringen).

\section{Conflicts of Interest}

The authors declare no conflicts of interest regarding the publication of this paper.

\section{References}

Adefila, A., Broughan, C., Phimister, D., \& Opie, J. (2020). Developing an Autonom- 
ous-Support Culture in Higher Education for Disabled Students. Disability and Health Journal, 13, Article ID: 100890. https://doi.org/10.1016/j.dhjo.2020.100890

Anderson, A. H., Carter, M., \& Stephenson, J. (2018). Perspectives of University Students with Autism Spectrum Disorder. Journal of Autism and Developmental Disorders, 48, 651-665. https://doi.org/10.1007/s10803-017-3257-3

Bencini, G. M. L., Garofolo, I., \& Arenghi, A. (2018). Implementing Universal Design and the ICF in Higher Education: Towards a Model That Achieves Quality Higher Education for All. Studies in Health Technology and Informatics, 256, 464-472.

Bolourian, Y., Zeedyk, S. M., \& Blacher, J. (2018). Autism and the University Experience: Narratives from Students with Neurodevelopmental Disorders. Journal of Autism and Developmental Disorders, 48, 3330-3343.

https://doi.org/10.1007/s10803-018-3599-5

D’Alessio, K. A., \& Banerjee, M. (2016). Academic Advising as an Intervention for College Students with ADHD. Journal of Postsecondary Education and Disability, 29, 109-121.

European Commission/EACEA/Eurydice (2014). Modernisation of Higher Education in Europe: Access, Retention and Employability.

Evans, W. (2014). I Am Not a Dyslexic Person I'm a Person with Dyslexia: Identity Constructions of Dyslexia among Students in Nurse Education. Journal of Advanced Nursing, 70, 360-372. https://doi.org/10.1111/jan.12199

Hauschildt, K., Vögtle, E. M., \& Gwosć, C. (2018). Eurostudent 2018. Social and Economic Conditions of Student Life in Europe, Eurostudent VI 2015-2018-Synopsis of Indicators. W. Bertelsmann Verlag. https://www.eurostudent.eu/

Järkestig Berggren, U., Rowan, D., Bergbäck, E., \& Blomberg, B. (2016). Disabled Students' Experiences of Higher Education in Sweden, the Czech Republic, and the United States-A Comparative Institutional Analysis. Disability and Society, 31, 339-356. https://doi.org/10.1080/09687599.2016.1174103

Lindgren, B. M., Lundman, B., \& Graneheim, U. H. (2020). Abstraction and Interpretation during the Qualitative Content Analysis Process. International Journal of Nursing Studies, 108, Article ID: 103632. https://doi.org/10.1016/j.ijnurstu.2020.103632

Majoko, T. (2018). Participation in Higher Education: Voices of Students with Disabilities. Cogent Education, 5, Article ID: 1542761. https://doi.org/10.1080/2331186X.2018.1542761

NVivo, Q. (2020). NVivo 1.1 Qualitative Research Software. https://www.qsrinternational.com/

Olofsson, A., Taube, K., \& Ahl, A. (2015). Academic Achievement of University Students with Dyslexia. Dyslexia, 21, 338-349. https://doi.org/10.1002/dys.1517

Polit, D. F., \& Beck, C. T. (2012). Nursing Research: Generating and Assessing Evidence for Nursing Practice (9th ed.). Lippincott Williams \& Wilkins.

Redpath, J., Kearney, P., Nicholl, P., Mulvenna, M., Wallace, J., \& Martin, S. (2013). A Qualitative Study of the Lived Experiences of Disabled Post-Transition Students in Higher Education Institutions in Northern Ireland. Studies in Higher Education, 38, 1334-1350. https://doi.org/10.1080/03075079.2011.622746

Richardson, J. T., Long, G. L., \& Woodley, A. (2004). Students with an Undisclosed Hearing Loss: A Challenge for Academic Access, Progress, and Success? The Journal of Deaf Studies and Deaf Education, 9, 427-441.

https://doi.org/10.1093/deafed/enh044

SFS1992:1434. Högskolelagen (Higher Education Act). Ministry of Education and Re- 
search.

SFS2008:567. Diskrimineringslagen (Discrimination Act). Ministry of Employment, Sweden.

Simmeborn Fleischer, A., Adolfsson, M., \& Granlund, M. (2013). Students with Disabilities in Higher Education-Perceptions of Support Needs and Received Support: A Pilot Study. International Journal of Rehabilitation Research, 36, 330-338.

https://doi.org/10.1097/MRR.0b013e328362491c

Stockholm University (2019). Årsredovisning 2019 (Annual Report 2019).

Swedish Higher Education Authority (2019). Higher Education Institutions in Sweden-2019 Status Report.

https://english.uka.se/about-us/publications/reports--guidelines/reports--guidelines/20 19-08-14-higher-education-institutions-in-sweden---2019-status-report.html

United Nations (2020). The 2030 Agenda for Sustainable Development, Goal 4: Ensure Inclusive and Equitable Quality Education and Promote Lifelong Learning Opportunities for All. https://sdgs.un.org/goals/goal4 